\title{
MORTEZ: MOBİL UYGULAMA DESTEKLİ ORTEZ SISTEMİ TASARIMI
}

\author{
Orhan GÜNDÜZ1 ${ }^{1}$ Cengiz TEPE², Nurettin ŞENYER $^{3 *}$ \\ ${ }^{1}$ Aygün Cerrahi Aletler, Ar-Ge Bölümü, Samsun, Türkiye \\ 2 Ondokuz Mayıs Üniversitesi, Mühendislik Fakültesi, Elektrik Elektronik Mühendisliği Bölümü, Samsun, Türkiye \\ ${ }^{3}$ Samsun Üniversitesi, Mühendislik Fakültesi, Yazılım Mühendisliği Bölümü, Samsun, Türkiye
}

\begin{tabular}{l} 
Anahtar Kelimeler \\
\hline Akıllı Ortez, \\
STM32, \\
Giyilebilir Teknolojiler, \\
Mobil Uygulama, \\
Taşınabilir Aygıt.
\end{tabular}

Öz

Beyne giden hayati kan ve oksijen akışının ani kesilmesiyle, ilintide olduğu bölgedeki hücrelerin ölmesiyle kısmi felç meydana gelir. Kişilerin tedavi süreçlerini hızlandırmak için ortez kullanımı bir ihtiyaçtır. Kişilerin konforunu korumak adına rehabilitasyon hizmetlerini ev ortamında almaları gerekir. Ayrıca Covid-19 gibi pandemi durumlarında ve diğer hastalıklardan korunmak için ortez kullanımında bireysel çözüm üretilmesi önemlidir. Günümüzde taşınabilir aygıtlar hayatımızın her köşesinde yer almaktadır. Hemen hemen her ailede en az bir tane akıllı telefon veya tablet gibi taşınabilir aygıt bulunmaktadır. Bu çalıșmada bir taşınabilir aygıta yüklenebilecek Mobil Uygulama Destekli Ortez (MORTEZ) arayüzü ile ARM tabanlı STM32 serisi bir mikrodenetleyicinin, bluetooh modülü kullanılarak haberleşmesi sağlanmıştır. Orteze entegre edilebilen enkoder üzerinden açı/konum bilgisi MORTEZ üzerinden animasyonlu bir șekilde izlenebilmektedir. Ayrıca gönderilen veriler MORTEZ yardımıyla taşınabilir aygıta kayıt edilebilmektedir. Yapılan bu çalışma, ortez kontrolünün ve rehabilitasyon süreçlerinin taşınabilir aygıt vasıtasıyla gerçekleştirebilir bir sistem tasarımının ilk adımını oluşturmaktadır. Ayrıca açıölçer ile akıllı telefon üzerinden görülen açı bilgisinin doğrulaması yapılmıştır ve 1 derecelik hassasiyetle doğru bir şekilde çalıștığı gözlemlenmiştir.

\section{MORTEZ: MOBILE APPLICATION SUPPORTED ORTHOSIS SYSTEM DESIGN}

\begin{tabular}{l}
\hline Keywords \\
\hline Smart Orthosis, \\
STM32, \\
Wearable Technologies, \\
Mobile Application, \\
Portable Device.
\end{tabular}

\begin{abstract}
The use of orthoses is a necessity to accelerate the partial paralysis treatment processes of people. In order to protect the comfort of people, they should receive rehabilitation services at home. In addition, it is important to produce an individual solution in the use of orthoses to protect against pandemic situations such as Covid19 and other diseases. Today, portable devices are present in every aspect of our lives. Almost every family has at least one portable device such as a smartphone or tablet. In this study, communication between the Mobile Application Supported Orthosis (MORTEZ) interface, which can be installed on a portable device, and an ARM-based STM32 series microcontroller using the bluetooh module is provided. Angle/position information can be monitored animatedly with MORTEZ via the encoder that can be integrated into the orthosis. In addition, the sent data can be saved to the portable device with the help of MORTEZ. This study constitutes the first step of designing a system that can perform orthosis control and rehabilitation processes with a portable device. In addition, the angle information monitored on the smartphone with the goniometer was verified and it was observed that it works correctly with 1 degree accuracy.
\end{abstract}

\section{Alıntı / Cite}

Gündüz, O., Tepe, C., Şenyer, N., (2021). MORTEZ: Mobil Uygulama Destekli Ortez Sistemi Tasarımı, Mühendislik Bilimleri ve Tasarım Dergisi, 9(3), 923-930.

\begin{tabular}{l|l|l}
\hline Yazar Kimliği / Author ID (ORCID Number) & \multicolumn{3}{|l}{ Makale Süreci / Article Process } \\
\hline O. Gündüz, 0000-0002-8132-8301 & Başvuru Tarihi / Submission Date & 04.03 .2021 \\
C. Tepe, 0000-0003-4065-5207 & Revizyon Tarihi / Revision Date & 09.06 .2021 \\
N. Şenyer, 0000-0002-2324-9285 & Kabul Tarihi / Accepted Date & 24.06 .2021 \\
& Yayım Tarihi / Published Date & 21.09 .2021 \\
\hline
\end{tabular}

\footnotetext{
* ilgili yazar / Corresponding author: nurettin.senyer@gmail.com, +90-505-405-0650
} 


\section{Giriş (Introduction)}

Ortezler, insan vücudunun ilgili bölgelerini desteklemek, düzeltmek veya o bölgedeki harekete yardımcı olmak için kullanılan medikal cihazlardır. Ortezlerin varlığı çok eski yıllara kadar uzanmaktadır ve yapılan çalışmalar, ortezlerin ilk kullanımlarının kırık ekstremitelere uygulanması olduğu göstermektedir (Alsancak, 2000). Günlük yaşamındaki hareketlerini, inme gibi çeșitli nedenlerden dolayı doğru gerçekleștiremeyen bireyler için ortez kullanımının iyileşme sürecini hızlandırıcı bir etkisi olduğu bilinmektedir. Rehabilitasyon hizmetlerinde ortezlerin ortak kullanımının yerine bireysel çözüm üretilmesi, ev rehabilitasyon sistemine dönüşmesi hastalık bulaşma riski ve konfor açısından önemlidir. Bunun için hafif, taşınabilir modüler bir ortez sistemi gereklidir. Kılıç vd. yaptıkları çalışmalarında dirsek bölgesinde tendon yırtığı veya inflamasyonu olan hastalar tarafından kullanılması için hafif, mobil ve yüksek güç kapasitesine sahip aktif bir bilek ortez tasarımı gerçekleştirmiştir (Kılıç ve Doğan, 2017). Giyilebilir cihaz teknolojisinin gelişmesiyle birlikte, bu ürünlerin ortezlerde kullanımı artmaktadır. Ryser ve arkadaşları yaptıkları çalışmada EMG sinyalleri ölçülmesi için kendi içinde bluetooth modülü bulunan kol bandı kullanmıștır. Elin beş farklı hareketinin algılamasını yapmışlardır (Ryser vd., 2017).

Yaşanan teknolojik gelişmelerle birlikte gömülü sistemlerde kullanılan 8-bit mikrodenetleyiciler yerini 32-bit ve daha ileri teknolojiye sahip mikrodenetleyicilere bırakmaktadır. Mikrodenetleyici teknolojisinin ilerlemesi, ortezlerinin kontrolü için kullanılan birimlerinin kapasitesinin iyileşmesini sağlamaktadır. 32-bit mikrodenetleyici kullanılarak yapılan ortez çalışmalarına daha çok son yıllarda rastlanılmaktadır. Park ve arkadaşlarının diferansiyel mekanizmaya sahip bir ortez önerisinde bulundukları çalışmada 32-bit mikrodenetleyici kullanmışlardır (Park vd., 2017). Pylatiuk ve arkadaşlarının 2009 yılında yaptıkları çalışmada, cihazın kontrolünü PIC16F877 serisi 8-bit işlem yapabilme kabiliyetine sahip bir mikrodenetleyici ile gerçekleștirmişlerdir (Pylatiuk, 2009). Karabıyık ve arkadaşları, el bilek kısmi felçli hastalar için bilek rehabilitasyonu sağlamak için taşınabilir ve maliyet etkin bir cihaz geliştirmişlerdir. Cihaz kontrolünde Arduino Mega kartı kullanılmıştır ve temelinde 8-bit mikrodenetleyici bulunmaktadır (Karabıyık vd., 2019). Yapılan diğer çalışmada yürümeye yardımcı olması için diz ortezinde EMG sensörleri ve 32-bit işlemciye sahip STM32F4discovery kartı kullanılarak elektronik tasarımı ve sistem kontrolü yapılmıştır. Ayrıca ayağa monte edilen IMUs çoklu sensör birimi üzerinden kaydedilen verileri kullanarak yürüme pattern analizi yapmışlardır (Félix vd., 2017).

Sabani ve arkadaşları akıllı telefon ile bacak ortezin kontrol etmek ve izlemek amacıyla yaptıkları çalışmada, fizyoterapist ve doktorlara rehabilitasyon sürecini izleme ve kontrol etme imkanı sunmuştur (Sabani ve Jailani, 2015). Ateş ve arkadaşlarının yaptıkları çalışmada yeni bir el bilek pasif ortez tasarımını gerçekleștirmişlerdir. Arduino Nano kartı ile PC arasında veri aktarımı yapılarak pasif ortezin hareketi sağlanmıștır (Ates vd., 2013). Ferreira ve arkadaşları yaptıkları sistem kontrolünü Android sistemli akıllı telefonlara yüklenebilir uygulama yazılımı üzerinden sağlamışlardır. Akıllı telefon ile mikrodenetleyici arası veri iletişimi HC-05 bluetooth modülü kullanarak gerçekleștirmișlerdir (Ferreira vd., 2020). Sangha ve arkadașlarının giyilebilir bilek ortezinin tasarımı ve kontrolü ilgili yaptıkları çalışmada, FMG sensör sinyallerin kayıt edilmesinde kablosuz iletişim aracı olarak bluetooth modülü kullanmışlardır (Sangha vd., 2016).

Taşınabilir aygıtların hayatımızdaki önemi giderek artmaktadır. Gerek oyun amaçlı gerekse uygulama amaçlı taşınabilir aygıtlar için uygulama geliştirme faaliyetleri ve yapılan uygulamaları güncelleme gereksinimleri, uygulama yazılımı geliştirmenin önemini göstermektedir. Günümüz teknolojisinde taşınabilir aygıtlar üzerinde uygulama geliştirmek için hibrit ve native birçok uygulama geliştirme aracı bulunmaktadır. Bu çalışmada Google tarafından 2017 yılında oluşturulan hibrit Flutter frameworku kullanılmıştır. Ücretsiz ve açık kaynak kodlu olan Fluetter, IOS ve Android gibi mobil platformlarda sorunsuz bir şekilde mobil yazılım geliștirilmesine imkan vermektedir. Flutter temel olarak yazılım geliștirme kiti olan SDK ve kullanıcı arayüz kütüphanelerinin olduğu Framework birimlerden oluşmaktadır (Argenova, 2020). Flutter da uygulama tasarımı Dart programlama dili kullanılarak yapılmaktadır. Dart programlama dili C, C\#, Java ve JavaScript dillerine benzemektedir (Macit, 2020).

Günümüzde birçok sektörde sıklıkla kullanılan enkoderlerin medikal sektörde de kullanımı oldukça yaygındır. Dominguez ve arkadaşlarının yaptıkları çalışmada, diz bölgesindeki açı ölçümü için mutlak enkoder kullanılmıştır (Dominguez vd., 2013). Shan ve arkadaşlarının giyilebilir aktif diz ortez tasarımı ve kontrolü için yaptıkları çalışmada, diz açı ölçümü için sonsuz turlu potansiyometre kullanmışlardır (Shan vd., 2016). Açı ölçülmesiyle ilgili olarak Daud ve arkadaşları yaptıkları çalışmada 10 farklı kiloda ve boydaki insanlarla, bacak ortezini farklı hız modlarında deneyip açı ve zaman bilgisini kayıt altına alıp ölçümler yapmıștır (Daud vd., 2013). Daha önce geliştirmiş oldukları aktif el bilek ortezine, pasif ve dirençli egzersiz modlarını ekledikleri çalışmada, ortez konumu kullanılan servo motor üzerinden elde edilmiştir (Kılıç ve Başer, 2020). Elde edilen konum bilgisi gürültülü, hassasiyeti düșük ve doğruluğunun sağlanma ihtiyacı bulunmaktadır. Yapılan kaynak incelemelerinde ortez tasarımında, plastik, karbon fiber ve metal gibi çeșitli materyallerin kullanıldı̆̆ı görülmüștür. Horst, Tibion PK100 
biyonik bacak ortezinin geliştirilmesinde karşılaşılan mühendislik zorluklarını ve erken hasta geri bildirimlerini anlattı̆̆ çalışmada kullanılan ortez karbon fiberden yapılmıştır (Horst, 2009).

Bu çalışmada STM32F4 serisi mikrodenetleyici tarafından ortezlere kolayca monte edilebilecek enkoder ile açı bilgisinin hesaplanması yapılmıştır. Bluetooth modülü kullanılarak açı bilgisinin taşınabilir aygıta aktarılması sağlanmıştır ve taşınabilir aygıta yüklenebilen MORTEZ üzerinden yapılan hareket ve açı bilgisi animasyonlu bir şekilde izlenebilmektedir. Ayrıca veri kayıt sistemi oluşturulmuştur. Taşınabilir aygıta aktarılan veriler kayıt edebilme özelliğine sahiptir. Gelen veriler, istenildiğinde MOTREZ üzerindeki kayıt butonuna tıklanılarak belirli bir formatta kaydedilmektedir. Yapılan doğrulama çalışmasıyla enkoder üzerinden okunan ve akıllı telefona aktarılan açı bilgisinin 1 derecelik hassasiyetle doğru bir şekilde çalıştığı gözlemlenmiştir.

\section{Materyal ve Yöntem (Material and Method)}

Yapılan bu çalıșmada gömülü donanım olarak enkoder, STM32F4 serisi bir ișlemci ve kablosuz iletișim için HC-05 bluetooth modülü kullanılmıştır. Şekil 1'de yapılan çalışmada kullanılan bileșenlerin temel şaması gösterilmiştir.

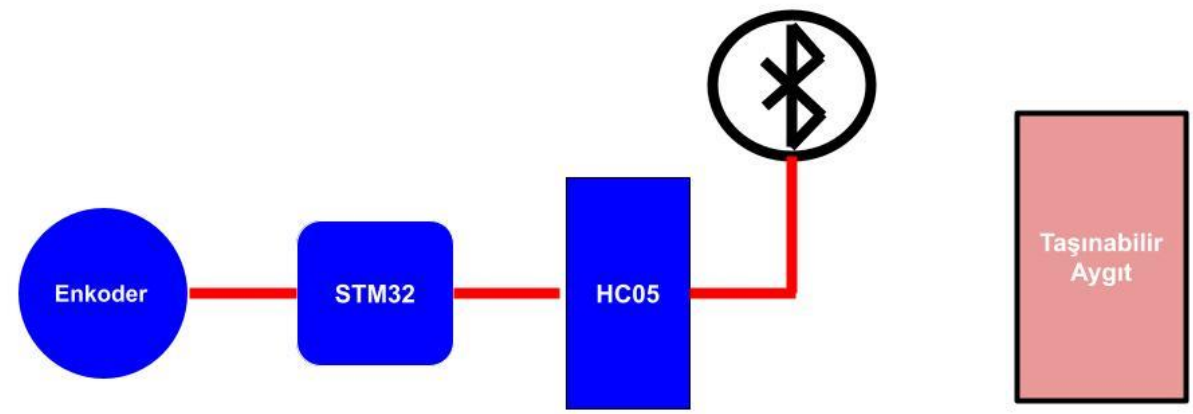

Şekil 1. Sistemin Temel Șeması (Basic Scheme of The System)

\subsection{Mobil Uygulama Arayüz Tasarımı (Mobile Application Interface Design)}

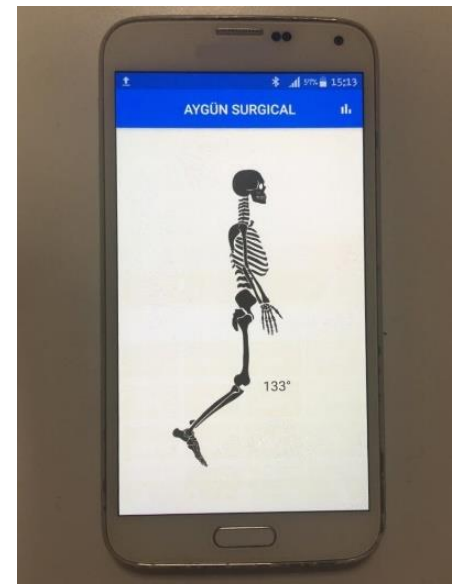

Şekil 2. MORTEZ Arayüzü (MORTEZ Interface)

Taşınabilir aygıt yazılımı Google tarafından 2017 yılında oluşturulan Flutter ile geliştirilmiștir. MORTEZ'in taşınabilir aygıt bileșeni üzerinde diz eklemindeki hareketinin simüle edilmesi, diz açısının enkoder ile algılanması ve taşınabilir aygıta aktarılması ile gerçekleștirilmektedir. Şekil 2'de MORTEZ görseli gösterilmektedir ve görselde bulunan açı değeri diz ekleminin yaptığı açıdır. Enkoder pozisyonunun her 1 derecelik değişimi, MORTEZ üzerinden görülmektedir. Telefon ile mikrodenetleyicinin veri alışverişi bluetooth üzerinden başarılı bir şekilde gerçekleştirilmiştir.

\subsection{Elektronik ve Gömülü Yazılım Tasarımı (Electronic and Embedded Software Design)}

Sistem elektronik olarak 3 bileșenden oluşmaktadır. Bunlar sistemin temelinde 32F429IDISCOVERY kartı olmak üzere HC-05 bluetooth modülü ve LPD3806-600BM enkoderdir. Modüllerin discovery kartı ile yaptıkları bağlantı Şekil 3'de bir tablo halinde gösterilmiştir. 


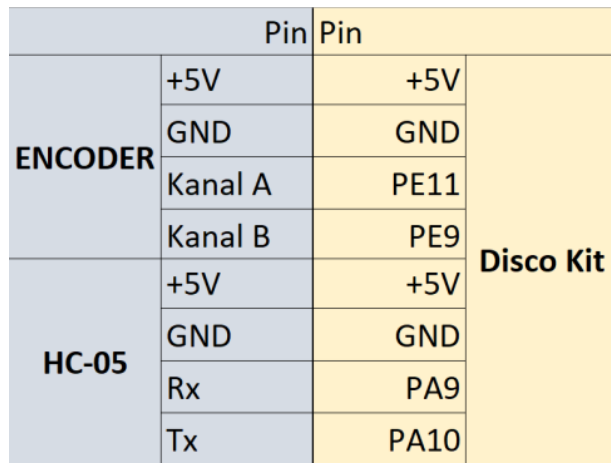

Şekil 3. Sistem Bağlantısı (System Connection)

Yapılan çalışmanın merkezinde 32F429IDISCOVERY kartı ve dolayısıyla STM32F429ZI mikrodenetleyicisi bulunmaktadır. Mikrodenetleyicinin çevre birimlerinin ayarlamasında, algoritmanın yazılım kodlarına dönüştürülmesinde ve program hatalarını düzeltilmesinde $\mathrm{C} / \mathrm{C}++$ geliştirme platformu olan STM32CubeIDE kullanılmıştır. STM32CubeIDE'nin birçok işletim sisteminde ücretsiz kullanılabilmesi ve ST-LINK desteklemesi gibi birçok tercih sebebini etkileyen faktörler vardır (STM32CubeIDE, 2020). Ayrıca değişken değerlerin izlenmesinde ve programın çalışma analizi yapılmasında STM-STUDIO programı kullanılmıștır.

Şekil 4'de yapılan çalışmanın algoritması temel seviyede gösterilmiştir. Burada enkoderden okunan açı değişimi, 1 dereceden büyük olursa HC-05 modülü ile taşınabilir aygıta aktarılmaktadır. İlk kullanımda ya da istenildiğinde ayakta durur vaziyette iken sıfırlama butonuna basılarak sisteminin açısı 180 derece olarak güncellenmektedir.

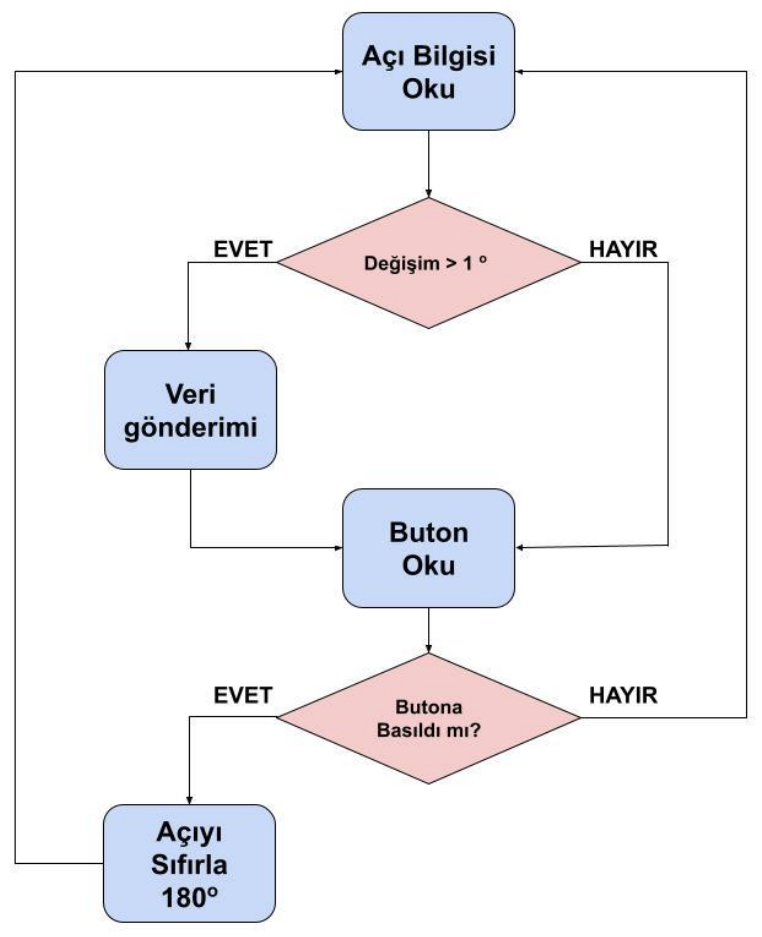

Şekil 4. Algoritma (Algorithmia)

\subsubsection{STM32F429 Kartı (STM32F429 Kit)}

$\mathrm{Bu}$ çalıșmada gömülü sistem olarak 32F429IDISCOVERY kartı kullanılmıștır. Kendi içerisinde program yazma/silme vb. gibi işlemleri yapılmasını sağlayan araç bulunmaktadır. Yapılan bu çalışmada Şekil 5'de gösterilen 32F429IDISCOVERY kartının kullanılmasının en önemli sebepleri arasında, üzerindeki mikrodenetleyicinin sahip olduğu bir takım özellikler, dokunmatik ekrana sahip olması, boyutu, ekonomik olması ve kolay temin edilmesi yer almaktadır. 


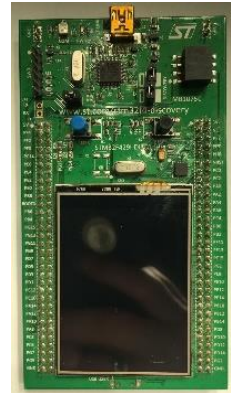

Şekil 5. 32F429IDISCOVERY Kartı (32F429IDISCOVERY Kit)

Discovery kartının üzerinde Arm tabanlı 32-bit, yüksek hızlı, 2Mbyte Flaş ve 256 Kbyte RAM'i olan bir mikrodenetleyici bulunmaktadır (32F429IDISCOVERY, 2020). Birçok modüle sahip olan mikrodenetleyicinin bu uygulamada UART ve Timer modülleri kullanılmıștır. Sahip olduğu bu özellikler sayesinde çalıșmanın sonraki evrelerinde kullanılmasına olanak sağlayacaktır.

\subsubsection{Bluetooth Modülü (Bluetooth Module)}

Bluetooth modülü olarak Bluetooth 2.0 destekleyen HC-05 kullanılmıștır. Bu modül 2.4 Ghz frekans bandında haberleşme sağlamaktadır. 460800 baud hızına kadar iletişimi desteklemektedir ve bu uygulamada 9600 standart değeri kullanılmıştır (HC-05, 2010). Bağlantı öncesi şifre kullanılarak doğrulamalı bağlantı protokolü kullanılmıştır. Şekil 6'da gösterilen HC-05 bluetooth modülü, kullanımı kolay ve yaygın olarak kullanılan bir seri port protokol modülüdür. Özellikle robotik ve medikal projelerde yaygın olarak kullanılmaktadır.

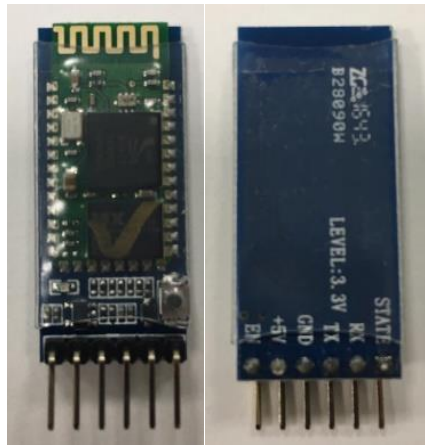

Şekil 6. HC-05 Bluetooth Modülü (HC-05 Bluetooth Module)

\subsubsection{ENKODER (ENCODER)}

Ortezlerin kullanıldıkları bölgede yapılan ekstansiyon ya da fleksiyon hareketinin miktarını ölçmek için enkoder veya potansiyometre gibi bileşenler kullanılmaktadır. Potansiyometre ekonomik bir ürün olmasına rağmen diz eklem açı hesabının direnç hesapları ile yapılacak olması ve hassasiyetinin düşük olması nedeniyle bu çalışmada enkoder kullanılmıștır. Enkoderler mutlak ve artırımlı olmak üzere iki tipi bulunmaktadır. Yapılan bu çalıșmada Şekil 7'de görülen artımlı enkoder (Enkoder, 2020) kullanılmıştır.

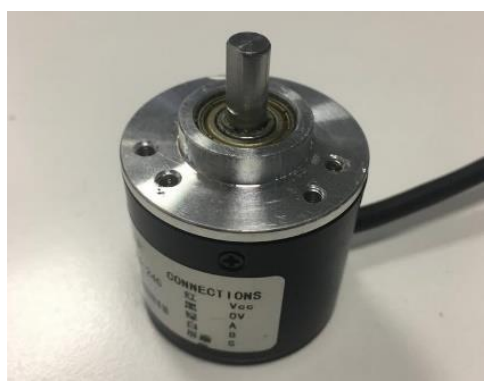

Şekil 7. Enkoder (Encoder)

Artırımlı enkoder enerjisi kesildikten sonra konum bilgisini koruyamamaktadırlar. Bu sebepten dolayı ilk enerji verildiği anda kalibrasyon ayarının yapılması gerekir. İlk enerji verildiğinde, ayakta dururken sıfırlama butonuna basıldığında, gömülü yazılım tarafından diz bölgesinin açısı 180 derece olarak güncellenmektedir. Ayrıca enkoderin hızlı döndürülmesi gibi çeşitli sebeplerden kaynaklı adım kaçırma durumları olabilmektedir. Bu neden dolayı yine aynı buton kullanılarak yeniden açı bilgisi güncellenebilmektedir. Enkoder 5-24 VDC arası gerilimle 
çalışabilir özelliğe sahiptir ve çalıșmada $5 \mathrm{~V}$ ile beslenmiștir. Her bir tur için 600 kare dalga üretmektedir. Bu çalışmada konum değişim hassasiyeti 1 derece olarak seçilmiştir. Enkoderdeki 1 derecelik konum değişimi bluetooth üzerinden MORTEZ'e aktarılmaktadır.

\subsection{Mekanik Tasarım (Mechanical Design)}

Yapılan çalışmada ortez sistemin mekanik tasarımı, diğer metallere göre daha hafif olması, maliyeti düşük olması ve hızlı bir şekilde ilk prototipinin üretilebilmesi için alüminyum metal kullanılarak yapılmıştır. Bu çalışmada asıl amaç bir akıllı ortez kontrol sistemi tasarlamak olduğu için yapılan mekanik tasarımında konfor, rahatlık ve mobilite ikinci planda tutulmuştur. Gerçeklenen bu tasarım Şekil 8'de gösterilmiştir.

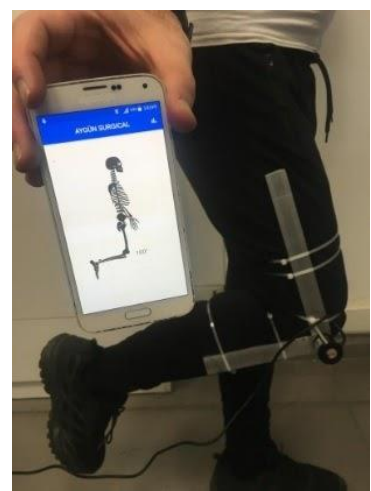

Şekil 8. MORTEZ Sistemi Genel Görünüm (Genereal View of MORTEZ System)

\subsection{Doğrulama (Verification)}

Yapılan çalışmada mekanik denemelere geçmeden önce, Sekil 9'daki gibi açıölçer kullanılarak bir doğrulama sistemi oluşturulmuştur. Yaplan bu sistemin amacı, enkoder üzerinden okunan açı bilgisini doğrulamaktır. MORTEZ üzerindeki açı bilgisi ile açı̈lç̧erin merkezine yerleştirilen imlecin gösterdiği açı bilgisi incelenerek karşılaştırılmıştır. Açıölçer, enkoderin gövdesine merkezli ve sabit olacak şekilde montaj edilmiştir. İmleç 180 dereceye getirilip discovery kartı üzerindeki butona basılarak konum sıfırlama yapılmıştır. Sonrasında enkoder miline bağlı olan imleç hareket ettirilerek, açıölçer üzerinde görülen açının MORTEZ üzerinden doğruluğu kontrol edilmiştir. Yapılan bu işlem MORTEZ üzerindeki açı bilgisinin 1 derecelik hassasiyetle çalıştığını doğrulamıştır.

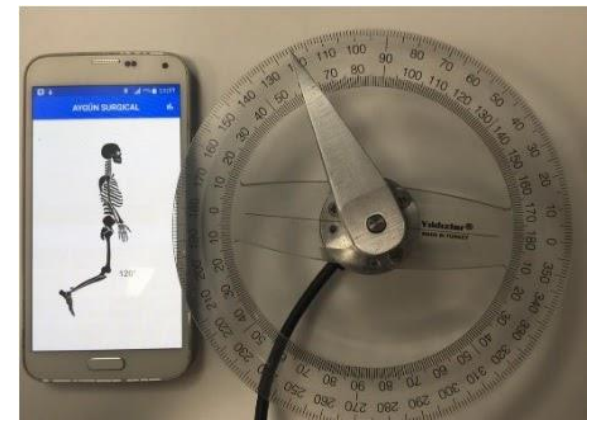

Şekil 9. Açıölçer ile Doğrulama (Verification With Protractor)

\section{Bulgular (Results)}

Yapılan ortez sistemi sağlıklı bir insanın sağ diz bölgesine monte edilerek açı okuma çalışması yapılmıștır. Kiși ayakta dururken diz bölgesinin açısı 180 derece olarak sıfırlama yapılmıştır. Diz fleksiyon hareketi ile yapılan çalışma üç kez tekrarlanmış ve 407 adet açı verisi kaydedilmiştir. Elde edilen veriler incelendiğinde diz açısı 60 ile 180 arası değişim göstermektedir. Şekil 10'da kaydedilen açı verilerden elde edilen grafik gösterilmiştir. Şekil 11 'de ise MORTEZ yazılımının, gelen açı verilerini kullanılarak oluşturduğu anlık grafiği gösterilmektedir. 


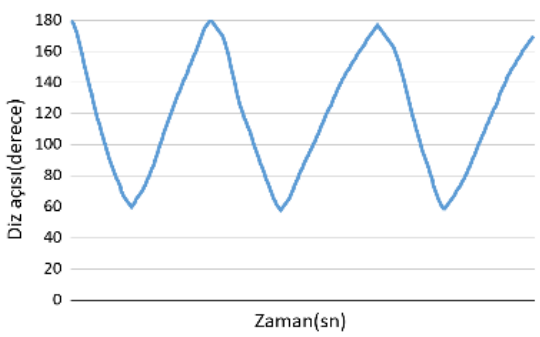

Şekil 10. Kaydedilmiş Verilerden Oluşturulmuş Grafik (Graph Created From Recorded Data)

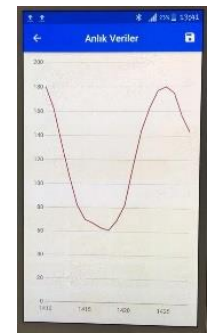

Şekil 11. MORTEZ Üzerinde Görülen Grafik (The Graph Seen on MORTEZ)

Telefona aktarılan veriler Tablo 1'de gösterilmiştir. Bu veriler zaman dilimine göre mikrosaniye ölçeğinde csv formatında kaydedilmektedir.

Tablo 1. Veri Kayıt Dosyası Örneği (Sample of Datalog File)

\begin{tabular}{|c|c|c|}
\hline Tarih & Zaman & Derece \\
\hline $2 / 8 / 2021$ & $16: 41: 36.573567$ & 180 \\
\hline $2 / 8 / 2021$ & $16: 41: 36.573751$ & 179 \\
\hline $2 / 8 / 2021$ & $16: 41: 36.573911$ & 178 \\
\hline $2 / 8 / 2021$ & $16: 41: 36.574064$ & 176 \\
\hline $2 / 8 / 2021$ & $16: 41: 36.574200$ & 174 \\
\hline $2 / 8 / 2021$ & $16: 41: 36.601525$ & 172 \\
\hline $2 / 8 / 2021$ & $16: 41: 36.601744$ & 169 \\
\hline $2 / 8 / 2021$ & $16: 41: 36.601943$ & 166 \\
\hline $2 / 8 / 2021$ & $16: 41: 36.623743$ & 163 \\
\hline $2 / 8 / 2021$ & $16: 41: 36.623922$ & 160 \\
\hline $2 / 8 / 2021$ & $16: 41: 36.624079$ & 157 \\
\hline $2 / 8 / 2021$ & $16: 41: 36.640355$ & 153 \\
\hline $2 / 8 / 2021$ & $16: 41: 36.659458$ & 150 \\
\hline
\end{tabular}

\section{Sonuç ve Tartışma (Result and Discussion)}

Bu çalışmada, taşınabilir aygıt vasıtasıyla kontrol edilebilir ortez sistemi ve rehabilitasyon süreç yönetimine katkı sağlayacak MORTEZ tasarlanmıștır. MORTEZ ile enkoder üzerinden okunan açının her 1 derecelik değișimi Bluetooth üzerinden tașınabilir aygıta bașarıyla aktarılmıștır. Gelen açı bilgisine göre kullanıcıya hareketli bir görsel sunulmuştur. Böylelikle kullanıcı yaptığı hareketleri hem görsel hem de derece biriminden yazılı olarak görebilmektedir. Ayrıca veriler kayıt altına alınabilmektedir. Bu kayıtları kullanarak hekimlere kullanıcının ortez kullanımını detaylı analiz etmesini de sağlayacak bir karar destek görevi de sunmaktadır. MORTEZ üzerinden okunan açı bilgisi, yapılan doğrulama çalışması ile doğruluğu test edilerek, başarılı sonuç elde edilmiştir.

Açı ölçümü, farklı hassasiyetlerde enkoder, ivme ve jiroskop kullanılarak bu çalışmanın genișletilmesi mümkündür. Ayrıca haberleşme protokolündeki baud hızı değiștirilerek mobil yazılım ile bir saniyede okunan veri sayısı artırılabilir. Gelecek çalışmada ilgili eklemin açı bilgisi ile birlikte EMG işaretlerinin de mobil yazılım üzerinden kayıt altına alınması da mümkündür. Hekime tanı koymasında yardımcı olmak adına kayıt altına alınan EMG işaretlerinin makine öğrenmesi temelinde Karar Destek Sistemi geliştirmesi sağlanabilir.

\section{Çıkar Çatışması (Conflict of Interest)}

Yazar tarafından herhangi bir çıkar çatışması beyan edilmemiştir. No conflict of interest was declared by the authors. 


\section{Kaynaklar (References)}

Alsancak, S. (2000). Ortez ve Protez Tarihçesi . Ankara Sağllk Hizmetleri Dergisi , 1 (1) , 27-33 . DOI: 10.1501 /Ashd_0000000003.

Argenova. (2020). Flutter Nedir ve Neden Öğrenmek Gerekir?. 25 Ocak 2021 tarihinde https://www.argenova.com.tr/flutternedir-ve-neden-ogrenmek-gerekir adresinden erişildi.

Ates, S., Lobo-Prat, J., Lammertse, P., Kooij, H., \& Stienen, A. (2013). SCRIPT Passive Orthosis: Design and technical evaluation of the wrist and hand orthosis for rehabilitation training at home. 2013 IEEE 13th International Conference on Rehabilitation Robotics (ICORR), 1-6.

Daud, M., Jailani, R., \& Al-Assadi, H.M. (2013). The development of motor based leg orthosis for leg exercise. 2013 IEEE 3rd International Conference on System Engineering and Technology, 400-405.

Dominguez, G., Cardiel, E., Arias, S., \& Hernández, P.R. (2013). A Digital Goniometer based on encoders for measuring knee-joint position in an orthosis. 2013 World Congress on Nature and Biologically Inspired Computing, 1-4.

Enkoder. (2020). DomoticX Knowledge Center. 5 Şubat 2021 tarihinde http://domoticx.com/sensor-lpd3806-optical-rotaryencoder/ adresinden erişildi.

Félix, P., Figueiredo, J., Santos, C.P., \& Moreno, J. (2017). Electronic design and validation of Powered Knee Orthosis system embedded with wearable sensors. 2017 IEEE International Conference on Autonomous Robot Systems and Competitions (ICARSC), 110-115.

Ferreira, F.M., Rúbio, G.D., Brandão, F.H., Mata, A.M., Avellar, N.B., Bonfim, J.P., Tonelli, L.G., Silva, T.X., Dutra, R.M., Petten, A.M., Vimieiro, C. (2020). ROBOTIC ORTHOSIS FOR UPPER LIMB REHABILITATION.

HC-05. (2010). Bluetooth to Serial Port Module. https://components101.com/sites/default/files/component_datasheet/HC05\%20Datasheet.pdf.

Horst, R. (2009). A bio-robotic leg orthosis for rehabilitation and mobility enhancement. 2009 Annual International Conference of the IEEE Engineering in Medicine and Biology Society, 5030-5033.

Karabıyık, İ, Kılıç, E, Bayram, A. (2019). Bilek Rehabilitasyonu İçin Düşük Maliyetli Bir Taşinabilir Robotik Cihazin Geliştirmesi ve Kontrolü. Uludağ University Journal of The Faculty of Engineering , 24 (3) , 347-364 . DOI: 10.17482/uumfd.609524.

Kılıç, E, Başer, Ö. (2020). Bir bilek ortezi için pasif rehabilitasyon ve dirençli egzersiz uygulama modlarının geliştirilmesi. Mühendislik Bilimleri ve Tasarım Dergisi, 8 (1) , 33-41. DOI: 10.21923/jesd.524191.

Kılıç, E., Doğan, E. (2017). Aktif bir bilek ortez tasarimi ve üretimi. Gazi Üniversitesi Fen Bilimleri Dergisi Part C: Tasarım ve Teknoloji, 5 (1), 33-44 . Retrieved from https://dergipark.org.tr/tr/pub/gujsc/issue/28467/303412.

Macit, K. (2020). Flutter ve Dart nedir?. 25 Ocak 2021 tarihinde https://www.mobilhanem.com/flutter-nedir/ adresinden erişildi.

Park, J., Park, S., Park, C., Jung, S., Kim, C., Park, J.H., \& Choi, J. (2017). A robotic orthosis with a cable-differential mechanism. 2017 IEEE International Conference on Robotics and Automation (ICRA), 517-521.

Pylatiuk, C., Kargov, A., Gaiser, I., Werner, T., Schulz, S., Bretthauer, G. (2009). Design of a flexible fluidic actuation system for a hybrid elbow orthosis. 2009 IEEE International Conference on Rehabilitation Robotics, 167-171.

Ryser, F., Bützer, T.L., Held, J., Lambercy, O., \& Gassert, R. (2017). Fully embedded myoelectric control for a wearable robotic hand orthosis. 2017 International Conference on Rehabilitation Robotics (ICORR), 615-621.

Sabani, A.H., \& Jailani, R. (2015). Android based control and monitoring system for leg orthosis. 2015 IEEE 11th International Colloquium on Signal Processing \& Its Applications (CSPA), 40-45.

Sangha, S., Elnady, A., \& Menon, C. (2016). A compact robotic orthosis for wrist assistance. 2016 6th IEEE International Conference on Biomedical Robotics and Biomechatronics (BioRob), 1080-1085.

Shan, H., Jiang, C., Mao, Y., \& Wang, X. (2016). Design and control of a wearable active knee orthosis for walking assistance. 2016 IEEE 14th International Workshop on Advanced Motion Control (AMC), 51-56.

STM32CubeIDE, STMicroelectronic, https://www.st.com/en/developmenttools/stm32cubeide.html, (Erișim tarihi: 05/02/2021).

32F429IDISCOVERY, UM1670 Rev 5, https://www.st.com/resource/en/user_manual/dm00093903-discoverykit-with-stm32f429zi-mcustmicroelectronics.pdf, (Erişim tarihi: 25/01/2021). 